UDC 519.6

$10.23947 / 2587-8999-2019-2-2-67-75$

\title{
Pore space colmatation during the bimodal suspension flow through the porous medium
}

\section{I. Golubev**}

Moscow Institute of Physics and Technology, Dolgoprudny, Russia

The problem of filtration of bimodal suspension through a porous medium is considered in the work. The model based on the laws of mass conservation for particles and for liquid is investigated, as well as local laws of particle capture described by kinetic equations. This model allows to take into account the differences in the physical properties of the particles (for example, their size) unlike the known model for the same type of particles The model takes into account the possibility of remobilization of captured particles. The numerical simulation shows that this model reproduces experimental data that previously could not be reproduced in the traditional single-particle model.

Keywords: mathematical modeling, filtration, suspension, porous medium, particle capture, permeability reduction.

Introduction. The particles are retained in the pore space and, as a consequence, the porosity and permeability of the medium decrease when the suspension moves through the porous medium. The intensity of particle accumulation in the pore space depends on many parameters, for example, the filtration rate, the ratio of particle sizes and pore constrictions (pore «necks»). The particles do not penetrate inside, but settle on the surface of the porous medium, forming an external filtration crust with low permeability if the characteristic particle size is larger than the characteristic size of the pore «necks». The penetration of particles into the porous medium takes place, which is accompanied by the retention of part of the particles in the pore space if the characteristic particle size is smaller than the characteristic size of the pore constrictions. There are various mechanisms of retention of particles by the porous medium, such as deposition on the walls of the pores under the influence of gravity or due to collision with the walls when moving through winding channels, capture of particles by pore constrictions, clogging of pore constrictions by several particles (arch colmatation).

There is a phenomenological approach to the description of processes occurring in porous media. Several macroparameters are distinguished, with the help of which the properties of the porous medium as a whole are described. This approach allows us to reproduce the average macroscopic values characterizing a porous medium. In $[1,2]$ the model describing the motion of suspension of indistinguishable solid particles through the porous medium is constructed. In the future, the authors of [3] expanded the model by introducing a mechanism of particle mobilization responsible for the

\footnotetext{
** E-mail: $\underline{\text { w.golubev@ mail.ru }}$
} 
return of particles to the flow. Many experimental data (see, for example, $[1,2,4,5]$ ) well described in the model [1, 2]. A number of experimental data are available, such as [6], on the filtration of suspension with a wide particle size distribution, which cannot be interpreted in this model. The model takes into account the possibility of remobilization of trapped particles in this paper, in comparison with [7], as well as its validation in the case of filtration while maintaining the constant flow rate.

Statement of the problem. Mathematical model describing the process of filtration of a suspension consisting of two different types of particles through a sample of the porous medium was considered in this paper. The sign of belonging to a certain type can serve, for example, the geometric size of the particle. The compressibility of liquid, solid particles and porous medium can be neglected. Suppose also that the physical velocities of the particles and the carrier fluid coincide (the particles are completely carried away by the carrier phase). If the diameter of the particles exceeds 1 micron, then self-diffusion of particles in the liquid can be neglected [2]. The diffusion of particles and consider the one-dimensional flow also can be neglected. The law of conservation of mass for solid particles of the first type has the form:

$$
\frac{\partial}{\partial t}\left(\rho_{1}\left(\sigma_{1}+\varphi c_{1}\right)\right)+\frac{\partial}{\partial x}\left(\rho_{1} c_{1} u\right)=0,
$$

where $\varphi(x)$ is the porosity of the sample, $u$ is the filtration rate, $\sigma_{1}$ is the fraction of retained particles of the first type, $c_{1}$ is the concentration of particles of the first type in suspension, $\rho_{1}$ is the density of the substance of the particles of the first type.

Similarly, the law of conservation of mass for particles of the second type has the form:

$$
\frac{\partial}{\partial t}\left(\rho_{2}\left(\sigma_{2}+\varphi c_{2}\right)\right)+\frac{\partial}{\partial x}\left(\rho_{2} c_{2} u\right)=0 .
$$

Due to the assumption of incompressibility of particles it is possible in equations (1) and (2) to reduce the density of the substance of particles.

The law of mass conservation for a liquid taking into account its incompressibility and takes the form

$$
\frac{\partial}{\partial t}\left(\varphi\left(1-c_{1}-c_{2}\right)\right)+\frac{\partial}{\partial x}\left(\left(1-c_{1}-c_{2}\right) u\right)=0 .
$$

Taking into account the above designations have

where $\varphi_{0}$ is the initial porosity of the sample.

$$
\varphi=\varphi_{0}-\sigma_{1}-\sigma_{2}
$$

Adding the equations (1)-(3) and considering the connection (4), obtain that the filtration rate of the suspension does not depend on the coordinate:

$$
\frac{\partial u}{\partial x}=0
$$

It is necessary to specify the local laws of retention of particles of each type in a porous medium to close a system of equations (1), (2), (5), as well as to set the correct boundary and initial conditions. Let assume that the intensity of retention of particles in the porous medium is proportional to the filtration rate and their concentration by analogy with the work [2]:

$$
\frac{\partial \sigma_{i}}{\partial t}=\lambda_{i} u c_{i}
$$


where $i=1,2$, and $\lambda_{i}$ is the coefficient of particles capture. Denote $P$ as the pressure in the liquid, $\mu$ as the viscosity of the suspension. To describe the movement of the suspension through the sample, we will use Darcy's law of filtration:

$$
u=-\frac{k\left(\sigma_{1}+\sigma_{2}\right)}{\mu} \frac{\partial P}{\partial x} \text {. }
$$

In which the dependence of permeability on the fraction of captured particles is introduced by analogy with the single-particle model [2]:

$$
k\left(\sigma_{1}+\sigma_{2}\right)=k_{0}\left(1-\frac{\sigma_{1}+\sigma_{2}}{\varphi_{0}}\right)^{3} .
$$

Let consider the problem of injection of suspension with a constant concentration:

$$
\begin{aligned}
& c_{1}(0, t)=c_{i n 1}, \forall t>0, \\
& c_{2}(0, t)=c_{i n 2}, \forall t>0,
\end{aligned}
$$

Constant pressure drop is maintained on the sample:

$$
\begin{gathered}
P(0, t)=P_{\text {in }}, \forall t>0, \\
P(L, t)=P_{\text {out }}, \forall t>0,
\end{gathered}
$$

It is assumed that at the initial time the sample does not contain particles:

$$
\begin{aligned}
& \sigma_{1}(x, 0)=0, x \in[0, L], \\
& \sigma_{2}(x, 0)=0, x \in[0, L], \\
& c_{1}(x, 0)=0, x \in[0, L], \\
& c_{2}(x, 0)=0, x \in[0, L],
\end{aligned}
$$

Numerical Method. The formulated mathematical problem has no analytical solution in general case. For the numerical solution of the system of equations (1)-(11) a uniform spatial calculation grid is introduced: $x_{j}=j * h, j \in\left[0, \frac{L}{N-1}\right]$, where $L$ is the sample length, $h$ is the grid step, $N$ is the number of nodes in the grid. The finite-difference scheme is based on the grid-characteristic method [8], the essence of which is to reduce partial differential equations to ordinary differential equations along the characteristic curves:

$$
\frac{d x}{d t}=\frac{u}{\varphi}
$$

The filtration rate is calculated on each time layer by a given pressure field:

$$
u^{n}=\frac{P_{\text {in }}-P_{\text {out }}}{h \mu \sum_{j=0}^{N-1} \frac{1}{k_{j}^{n}}},
$$

where index $n$ denotes the time layer. Equation (12) is obtained by summing the discretized Darcy equation with equation (5) on the spatial computational grid. Then there are characteristic curves along each of which ordinary differential equations are solved

$$
\tilde{\mathrm{c}}_{1 j}^{n+1}=c_{1 j}^{n}+\Delta t\left(\frac{u^{n}}{\varphi_{j}^{n}} c_{1 j}^{n}\left(c_{1 j}^{n}-1\right) \lambda_{1}+\frac{u^{n}}{\varphi_{j}^{n}} c_{1 j}^{n} c_{2 j}^{n} \lambda_{2}\right),
$$




$$
\tilde{c}_{2 j}^{n+1}=c_{2 j}^{n}+\Delta t\left(\frac{u^{n}}{\varphi_{j}^{n}} c_{2 j}^{n}\left(c_{2 j}^{n}-1\right) \lambda_{2}+\frac{u^{n}}{\varphi_{j}^{n}} c_{2 j}^{n} c_{1 j}^{n} \lambda_{1}\right) .
$$

The result is the determination of the concentration of suspended particles at some points of the sample, different from the points of the grid:

$$
x_{j}^{n+1}=x_{j}^{n}+\frac{u^{n}}{\varphi_{j}^{n}} \Delta t
$$

After that, the particle concentration values are interpolated to a constant spatial grid.

The last step is to calculate the proportion of retained particles in each grid cell:

$$
\begin{aligned}
& \sigma_{1 j}^{n+1}=\sigma_{1 j}^{n}+\Delta t \lambda_{1} u^{n} c_{1 j}^{n+1}, \\
& \sigma_{2 j}^{n+1}=\sigma_{2 j}^{n}+\Delta t \lambda_{2} u^{n} c_{2 j}^{n+1} .
\end{aligned}
$$

The described scheme has the first order of accuracy in time and coordinate, and at the same time has the feature of accurately reproducing discontinuous solutions. Fig. 1 shows the result of simulation of injection of a two-particle suspension into a porous sample is presented. The model parameters are given in table 1 (№1). The front blur is zero cells in the spatial grid.

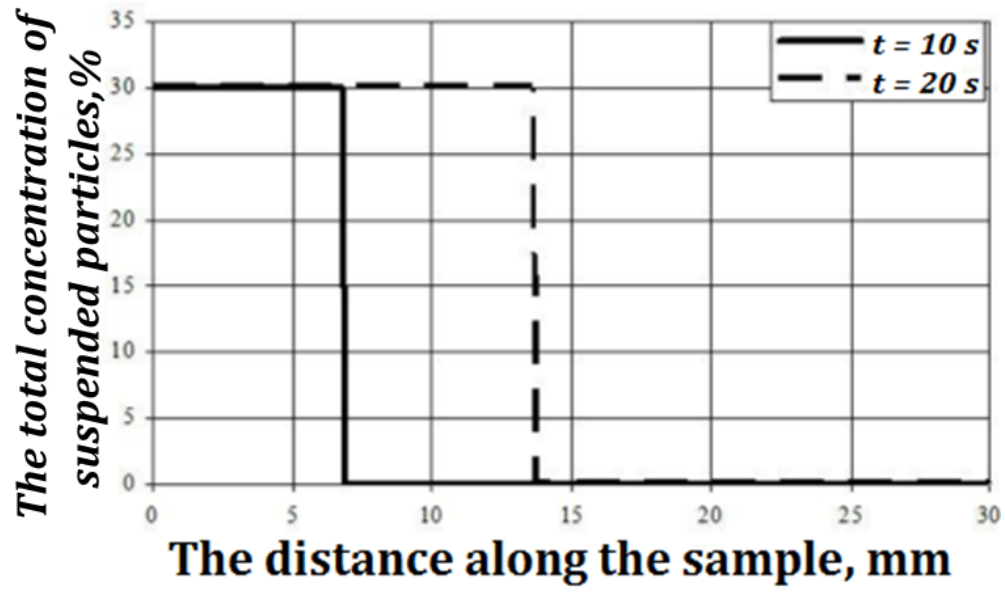

Fig. 1. Distribution of the total concentration of suspended particles along the sample for two time points

Table 1. Data for numerical simulations

\begin{tabular}{|l|l|l|l|l|l|l|l|l|l|}
\hline №. & $\mathrm{L}, \mathrm{cm}$ & $c_{\text {in1 }}, \%$ & $c_{\text {in } 2}, \%$ & $\varphi_{0}, \%$ & $\lambda_{1}, 1 / \mathrm{m}$ & $\lambda_{2}, 1 / \mathrm{m}$ & $k_{0}$, Darcy & $\begin{array}{l}\mu, \\
\mathrm{MPa} *_{\mathrm{s}}\end{array}$ & $\begin{array}{l}P_{\text {in }}- \\
P_{\text {out }}, \\
\mathrm{atm}\end{array}$ \\
\hline 1 & 3 & 10 & 20 & 20 & 0 & 0 & 0,6 & 30 & 2 \\
\hline 2 & 3 & 13 & 0,1 & 17 & 70 & 20000 & 0,6 & 30 & 20,4 \\
\hline
\end{tabular}

Experimental verification. The developed model was used to simulate the process of slurry injection into the porous sample. The data required for the simulation were taken from experimental work [6], where the results of a laboratory experiment on filtering $13 \%$ of the $\mathrm{CaCO}_{3}$ particle suspension through a Sandstone sample are presented. The measured viscosity of such a suspension was $30 \mathrm{MPa}^{*}$ s. the Cylindrical sample with length of $30 \mathrm{~mm}$ and a diameter of $25.4 \mathrm{~mm}$ had a porosity 
of $17 \%$ and a permeability of $600 \mathrm{MD}$. The constant pressure drop of 20.4 atm was maintained on the sample during the experiment., The distribution of the fraction of retained particles along the sample was measured at the end of the filtration process. The authors [6] used a single-particle model $[1,2]$ to describe the results of the experiment. However, as the authors note [6], not all experimental results were reproduced within the framework of this model.

Following the assumption of the authors [6], we will approximate the particle size distribution by bimodal distribution. The particle capture coefficient obviously has to increase with increasing particle size. Then the depth of penetration of the particles should decrease with increasing size. Fig. 2 shows the results of the simulation based on the two-particle model. Unknown parameters of the model, which are the concentration of particles of the second type and two capture coefficients, were determined on the basis of the best reproduction of experimental data. The parameters used for modeling are given in table 1 (№ 2). The simulation results well reproduce the trend in the experimental data, as well as the fracture (in the region of $0.2 \mathrm{~mm}$ from the entrance to the sample) on the distribution profile of the retained particles. They also support the assumption that large particles are held inside the sample near its entrance, while smaller particles pass deeper into the sample.

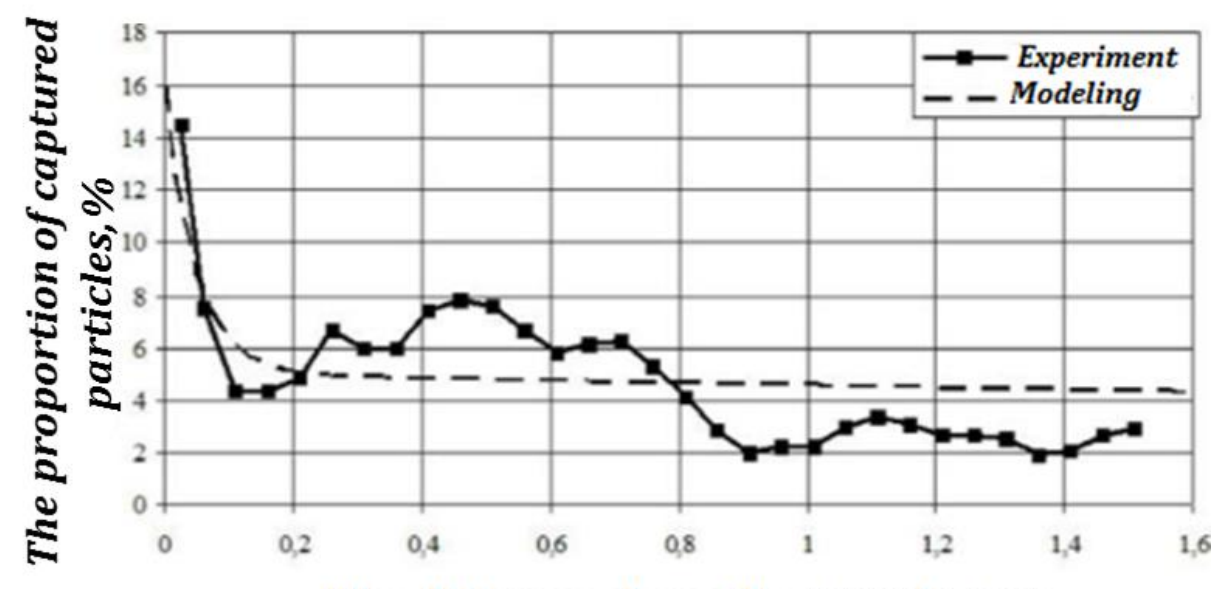

The distance along the sample, $\mathrm{mm}$

Fig. 2. Distribution of the fraction of captured particles along the sample. Experimental data are taken from [6]

In [4], the effect of the initial permeability of the sample, particle size distribution, and particle concentration on the process of filtration of the suspension through a porous medium was experimentally investigated. The experiments used samples of Berea Sandstone. The porosity range was $17-20 \%$ and the permeability range was $100-500 \mathrm{mD}$. The filtered suspension consisted of pure water and latex particles. The particle density was on the order of $1 \mathrm{~g} / \mathrm{cm}^{3}$. The viscosity of the suspension was $0.93-1.08 \mathrm{MPa}^{*} \mathrm{~s}$. Three different types of suspensions differing in particle size (diameters: $0,5-2 ; 0,5-3 ; 0,5-5,0 \mathrm{mkm}$ ). The concentration of the suspension varied in the range: 50 $200 \mathrm{mg} / 1$. two types of suspension filtration experiments are described: with maintaining a constant filtration rate and with maintaining a constant pressure drop on the sample during the entire experiment. Characteristic injection rates: $3-10 \mathrm{ml} / \mathrm{min}$, characteristic differential pressure was 40 psi. 
In the framework of the bimodal model, the experimental data corresponding to experiment № 22 from the article [4] were successfully reproduced. The input parameters were taken from the article: porosity was $19.09 \%$, permeability was $247.78 \mathrm{mD}$, constant pressure drop was 40 psi, slurry concentration at the inlet was $100 \mathrm{mg} / \mathrm{l}$, slurry viscosity was $1.03 \mathrm{MPa} * \mathrm{~s}$, particle density was 1.2 $\mathrm{g} / \mathrm{cm}^{3}$, sample length was $5 \mathrm{~cm}$. The dependence [3] was used to account for the possibility of returning previously deposited particles to the flow:

$$
\frac{\partial \sigma_{i}}{\partial t}=-\alpha_{i} \sigma_{i}\left(u-u_{c}\right), \text { if } u>u_{c},
$$

where $u_{c}$ is the minimum filtration rate at which this process is activated.

Table 2. Data for numerical simulations

\begin{tabular}{|l|l|l|l|l|l|l|l|l|l|c|c|}
\hline № & $\begin{array}{l}\mathrm{L}, \\
\mathrm{cm}\end{array}$ & $c_{\text {in1 }}, \%$ & $c_{\text {in2 }}, \%$ & $\varphi_{0}, \%$ & $\begin{array}{l}\lambda_{1}, \\
1 / \mathrm{m}\end{array}$ & $\begin{array}{l}\alpha_{1}, \\
1 / \mathrm{m}\end{array}$ & $\begin{array}{l}\lambda_{2}, \\
1 / \mathrm{m}\end{array}$ & $\begin{array}{l}\alpha_{2}, \\
1 / \mathrm{m}\end{array}$ & $\begin{array}{l}k_{0}, \\
\mathrm{mD}\end{array}$ & $\begin{array}{l}\mu, \\
\mathrm{MPa} \text { *s }\end{array}$ & $\begin{array}{l}P_{\text {in }}- \\
P_{\text {out }},\end{array}$, atm \\
\hline 1 & 5 & 0,004 & 0,004 & 19,09 & $10^{3}$ & 0,6 & 10 & 0 & 247,78 & 1,03 & 2,7 \\
\hline
\end{tabular}

Fig. 3 shows experimental results (black diamonds) and simulation results (blue solid line) are presented. You can see a good match of the results.

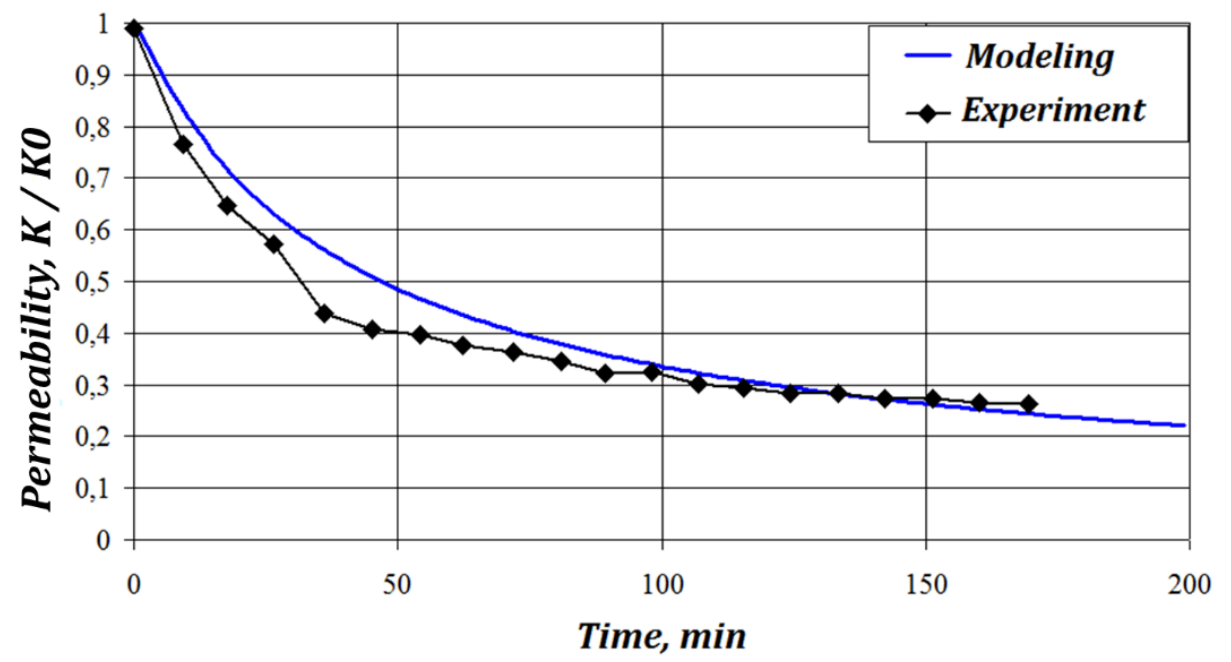

Fig. 3. Comparison of modeling and experimental results (experiment № 22 from [4])

In [9] a series of experiments on filtration of suspension through a porous medium at a constant filtration rate is described. In total, 6 experiments were carried out in the range of parameters: filtration rate was $5.4 \mathrm{l} / \mathrm{h}$ and $10 \mathrm{l} / \mathrm{h}$, suspension concentration was 20, 40, $80 \mathrm{mg} / \mathrm{l}$. Suspension consisted of water and hematite particles with a diameter of 0.1-5 microns. Benthein Sandstone sample had the shape of a cylinder with a diameter of $2.54 \mathrm{~cm}$ and a length of $12.7 \mathrm{~cm}$ and had a porosity of $22 \%$ and a permeability of $1.4 \mathrm{D}$. Along the axis of the sample, pressure meters were located so that the dynamics of the pressure drop was recorded at 6 sites. On the basis of these data, the permeability of these 6 sites as a function of time was calculated by the known filtration rate. After the end of each filtration experiment, the sample was split in a special machine for triaxial loads 
into pieces $2.54 \mathrm{~cm}$ long. Each piece was placed in a separate flask, where a certain amount of hydrochloric acid was added. The resulting mixture was subjected to heat treatment. As a result of this operation, it was possible to measure the concentration of Fe (using atomic absorption spectroscopy), and, accordingly, to calculate the mass of hematite that penetrated into this piece of the sample. In the framework of the bimodal model, numerical simulation was carried out with parameters corresponding to the parameters of experiment № 1 from [9]: suspension concentration was $20 \mathrm{mg} / \mathrm{l}$, hematite density was $5 \mathrm{~g} / \mathrm{cm}^{3}$, injection rate was $4.48 \mathrm{l} / \mathrm{h}$, the number of pumped volumes was 662.5. The results of modeling and experimental data were compared. Fig. 4 shows comparison of the mass of captured hematite in each part of the sample. Fig. 5 shows comparison of the mass of captured hematite normalized to the dimensionless length of the sample. A good agreement between the results of numerical simulation and the experiment was achieved. The following parameters were used in the simulation: the concentration of particles of the first type was $12.5 \mathrm{mg} / \mathrm{l}$, the coefficient of capture of particles of the first type was $3 \mathrm{~m}^{-1}$, the concentration of particles of the second type was $7.5 \mathrm{mg} / \mathrm{l}$, the coefficient of capture of particles of the second type was $50 \mathrm{~m}^{-1}$, the degree of permeability depending on the proportion of captured particles was 120 .

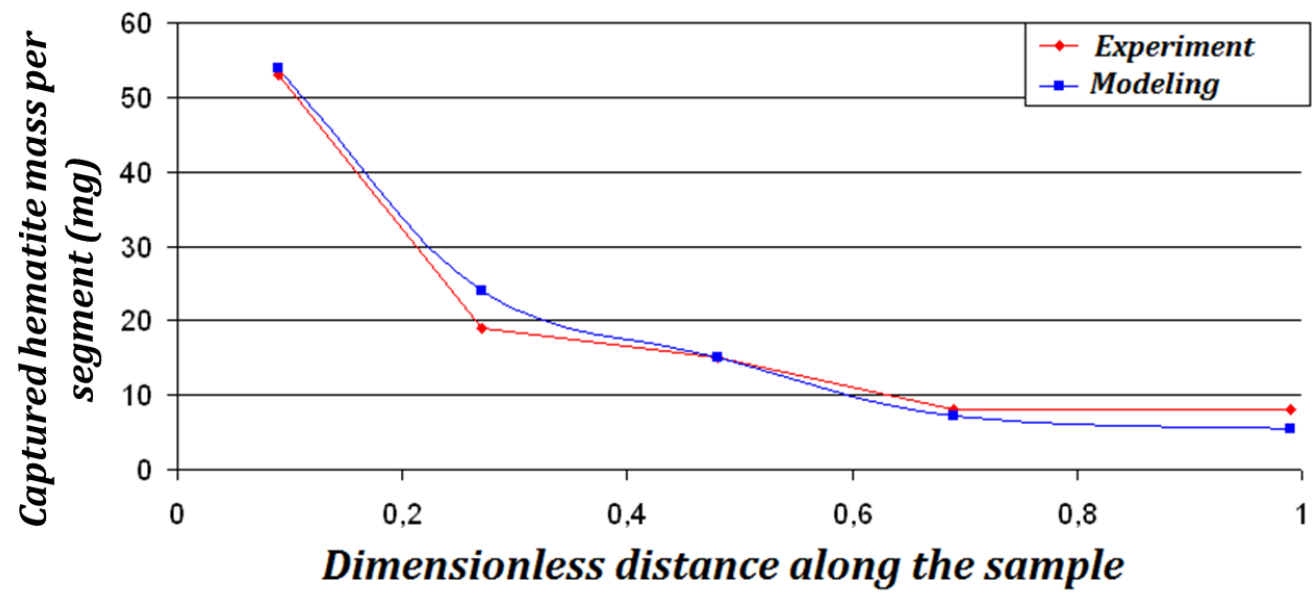

Fig. 4. Hematite mass-comparison of simulation and experimental results (experiment № 1 of [8])

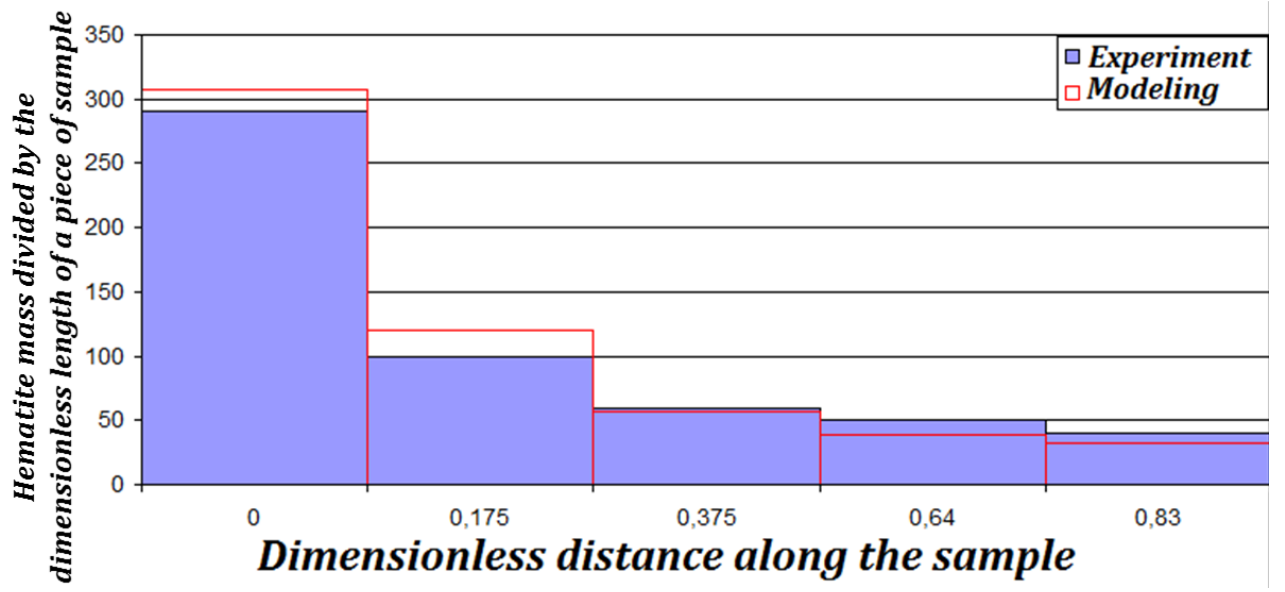

Fig. 5. The mass of hematite divided by the dimensionless length of the sample piece. Comparison of simulation and experimental results (experiment № 1 of [9]) 
Conclusion. The problem of bimodal suspension motion in a porous medium is considered in this paper. The model is used to describe the process of deposition of particles on its walls and, accordingly, the decrease in the permeability of the medium. It has been extended to take into account the possibility of re-involvement of precipitated particles in the flow when the critical flow rate is reached. A finite-difference scheme is presented that allows numerical calculation of this process. It is based on a grid-characteristic approach with reinterpolation to a fixed computational grid. Within the framework of the proposed model, a number of experimental data published in scientific articles by independent authors were successfully reproduced.

\section{References}

1. Iwasaki T. Some notes on sand filtration. // Journal of American Water Works Association. 1937. V. 29, N 10. P. 1591--1602.

2. Herzig J.P., Leclerc D.M., Goff P. Flow of Suspensions through Porous Media // Industrial and Engineering Chemistry. 1970. V. 62, N 5. P. 8--35.

3. Gruesbeck C., Collins R.E. Entrainment and Deposition of Fine Particles in Porous Media // SPE Journal. 1982. V. 22, N 6. P. 847--856.

4. Eleri O.O., J-R Ursin, Rogaland U. Physical Aspects of Formation Damage in Linear Flooding Experiments // SPE Symposium on Formation Damage Control. 1992.

5. Pang S., Sharma M.M. A Model for Predicting Injectivity Decline in Water-Injection Wells // SPE Annual Technical Conference and Exhibition. 1994. SPE 28489.

6. Bailey L., Boek E., Jacques S. [et al.] Particulate Invasion From Drilling Fluids // SPE European Formation Damage Conference. 1999. SPE 54762.

7. Golubev V.I., Mikhaylov D.N. Modelirovaniye dinamiki v dvukhchastichnoy suspenzii cherez poristuyu sredu // «Trudy MFTI» tom 3, № 2 (10) (2011), 143-147.

8. Magomedov K.M., Kholodov A.S. Setochno-signal'nyye chislennyye metody. M .: Nauka, 1988.

9. F.A.H. Al-Abduwani et al. «Formation damage vs. Solid particles deposition profile during laboratory-simulated produced-water reinjection», SPE Journal, June 2005, p. 138 - 151.

\section{Authors:}

Golubev Vasily Ivanovich, Moscow Institute of Physics and Technology (Institutsii per., 9, Dolgoprudny, Moscow Region, Russian Federation), к.ф.-м.н., Associate professor, Senior researcher 
УДК 519.6

$10.23947 / 2587-8999-2019-2-2-121-132$

Кольматация порового пространства при протекании бимодальной суспензии через пористую среду

\section{В.И. Голубев}

Московский физико-технический институт, Долгопрудный, Российская Федерация

Рассматривается задача фильтрации двухчастичной суспензии через пористую среду. Исследуется модель, основанная на законах сохранения массы для частиц и для жидкости, а также локальных законах захвата частиц, описываемых кинетическими уравнениями. В отличие от известной модели для однотипных частиц, данная модель позволяет учесть различия в физических свойствах частиц (например, их размере). В модели учитывается возможность повторной мобилизации захваченных частиц. Проведённое численное моделирование показывает, что данная модель воспроизводит экспериментальные данные, которые ранее не удалось воспроизвести в рамках традиционной одночастичной модели.

Ключевые слова: математическое моделирование, фильтрация, суспензия, пористая среда, захват частиц, уменьшение проницаемости.

\section{Авторы:}

Голубев Василий Иванович, Московский физико-технический институт (Институт пер., 9, Долгопрудный, Московская обл., Российская Федерация), к.ф.-м.н., доцент, старший научный сотрудник 